\title{
Nurses' clinical competence in psychiatric wards of selected hospital of University of Behzisti \& Tavanbakhshi, 2018-2019
}

\author{
Mohammad Hossein Karaminia ${ }^{1}$, Samaneh Parchehpafieh ${ }^{2}$, Sedigheh Maleki ${ }^{3}$, Aref Amirkhani ${ }^{4}$ \\ ${ }^{1}$ Psychiatrist Nurse, Besat Hospital, Hamadan University of Medical Sciences, Hamadan, Iran \\ ${ }^{2}$ Department of Nursing, Instructor, School of Nursing and Midwifery, Islamic Azad University of Medical Sciences, \\ Tehran, Iran \\ ${ }^{3}$ Department of Nursing, Instructor, School of Nursing and Midwifery, Islamic Azad University of Medical Sciences, \\ Tehran, Iran \\ ${ }^{4}$ Associate Professor, Department of Epidemiology and Statistics, School of Medicine, Islamic Azad University of \\ Medical Sciences, Tehran, Iran
}

\begin{abstract}
Background: Clinical competence in nursing profession has a unique position. The quality of care in the psychiatric wards, which include patients with special conditions, is important. Hence, nurses of these departments must have high clinical competency. The aim of this study was to determine the clinical competency of nurses working in psychiatric wards.

Materials and methods: In this descriptive cross-sectional study, 210 nurses working in psychiatric wards of selected hospitals of the University of Behzisti and Tavanbakhshi Sciences were selected by simple random sampling. After completing the demographic questionnaire, clinical function of nurses was assessed by a checklist of clinical competence scale in CCMHN psychiatric nurses. For data analysis, descriptive and inferential statistics were used in SPSS 21 software.

Results: Clinical competence was in a good level among $70.9 \%$ of clinical nurses. There was a significant association between work experience and clinical competency, work shift, and clinical competency, and overtime and clinical competence $(\mathrm{p}<0.05)$.

Conclusion: The results showed that the clinical competence of the nurses is desirable and there is a need for planning for its development. However, the need to plan work hours and avoid overtime in nurses, as well as the appropriate distribution of personnel based on work experience and constant staff shift can help to balance and improve the clinical competence of nurses.
\end{abstract}

Keywords: Clinical competency, Psychiatric nurses, Psychiatric wards.

Cited as: Karaminia MH, Parchebafieh S, Maleki S, Amirkhani A. Nurses' clinical competence in psychiatric wards of selected hospital of University of Behzisti \& Tavanbakhshi, 2018-2019. Medical Science Journal of Islamic Azad University, Tehran Medical Branch 2020; 30(3): 332-340.

Correspondence to: Samaneh Parchebafieh

Tel: +989122543795

E-mail: s.parchebaf@iautmu.ac.ir

ORCID ID: 0000-0003-2307-579

Received: 22 June 2019; Accepted: 17 Sep 2019 
مجله علوم يزشكى دانشگاه آزاد اسلامى

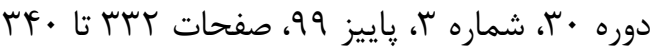

\section{شايستگى بالينى يرستاران شاغل در بخشهاى اعصاب و روان بيمارستان منتخب

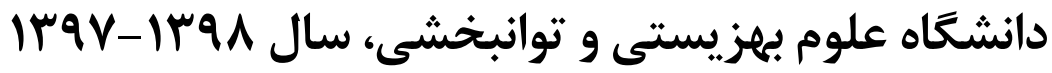

محمد حسين كرمى نيا'، سمانه يارجه بافيه؟، صديقه ملكى ‘، عارف اميرخانى

$$
\begin{aligned}
& \text { 'كارشناس ارشد روانبرستارى، بيمارستان بعثت، دانشعاه علوم يزشكى همدان، همدان، ايران }
\end{aligned}
$$

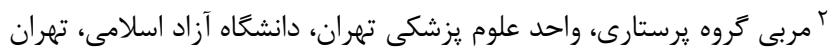

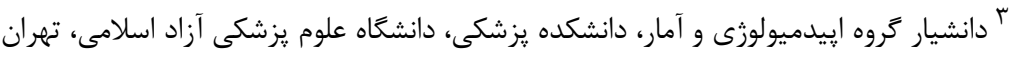

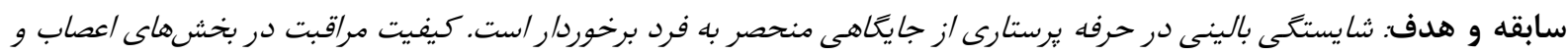

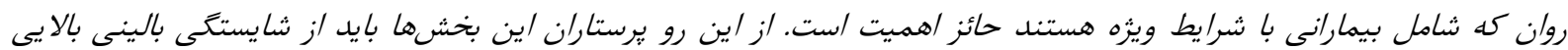

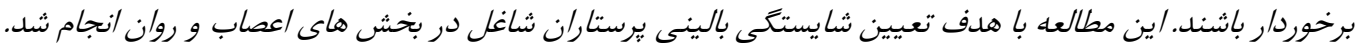

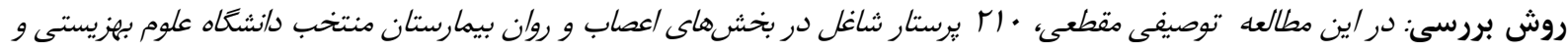

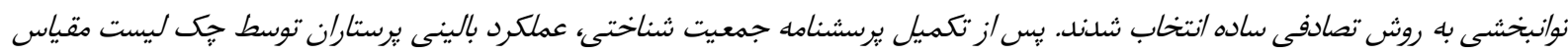

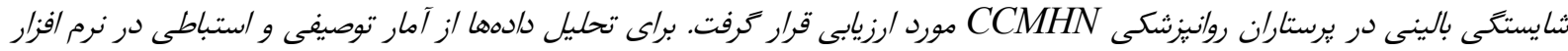
SPSS

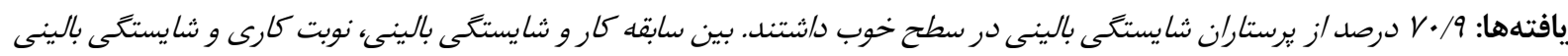

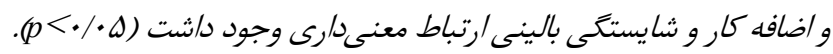

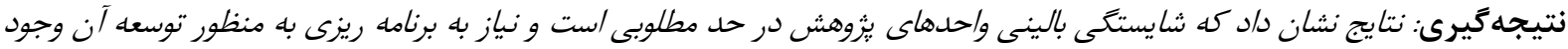

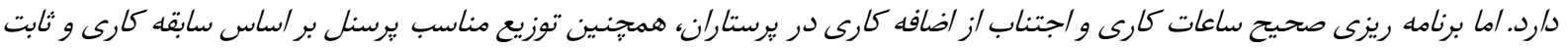

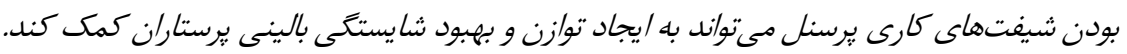

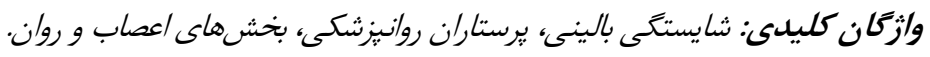

يرستارى و مفهوم كيفيت مراقبت سبب شده شايستخى در حرفـه

مقدمه

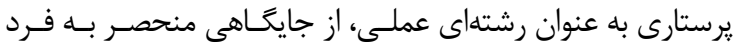
از مهمترين حوزه هاى توسعه يايـدار سـلامتى در جوامـع بشــى،

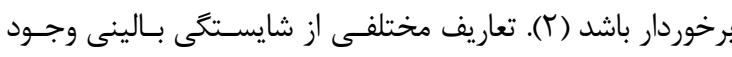

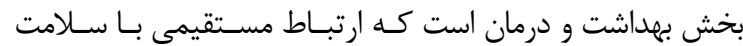

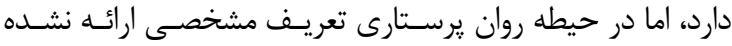

از ديدگاه مديريت، شايستخى بالينى برسـتارى عامـل مـوثرى در

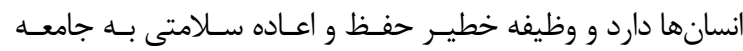

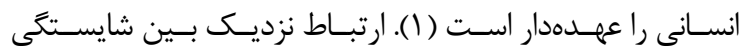

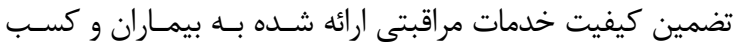

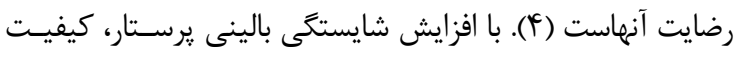

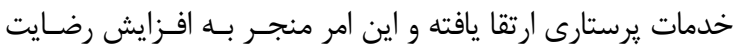

أدرس نويسنده مسئول: تهران، انتهاى بزركراه شهيد ستارى، ميدان دانشكاه،دانشكاه آزاد اسلامى، دانشكده.

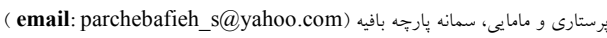
ORCID ID: 0000-0003-2307-579 تاريخ دريافت مقاله: تاريخ بذيرش مقاله: 9N/9/M9 
براى ارائه مراقبتهاى كيفى مناسب، حرفهاى و استاندارد نيازمنــد

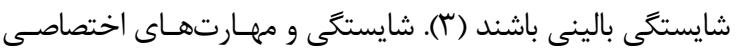

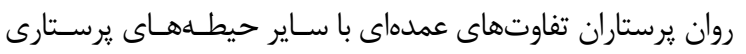

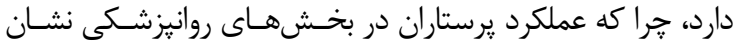

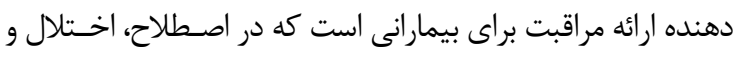

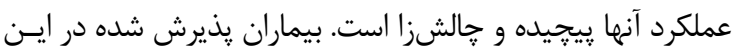

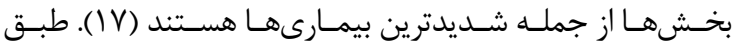

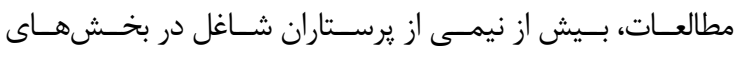

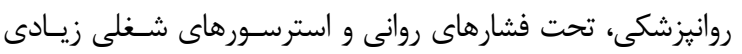

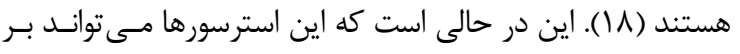

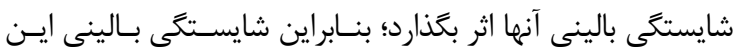

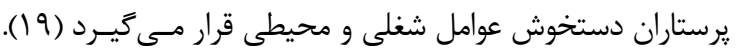

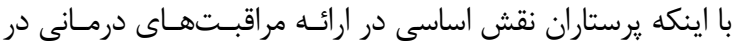

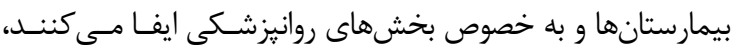

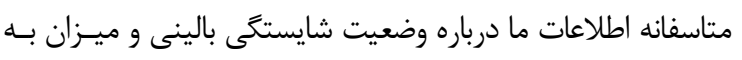
كاركيرى مهارتهاى يرستارى توسط روان يرستاران بسـيار انـدى

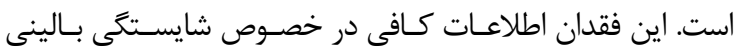

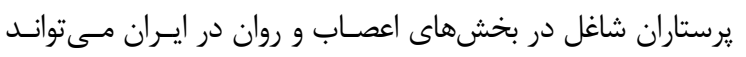

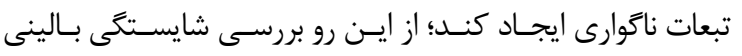

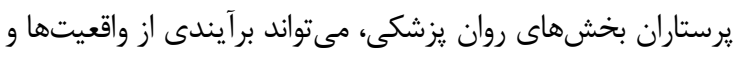

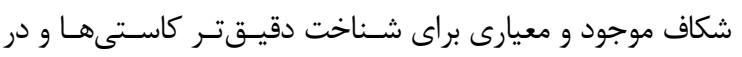

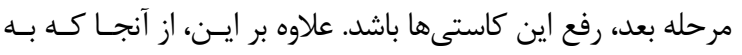

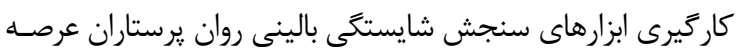

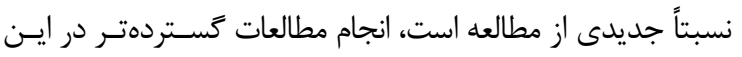

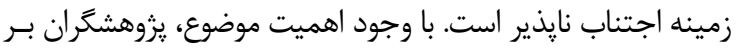

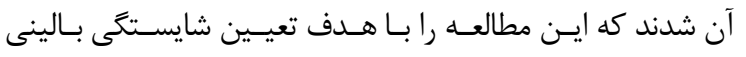

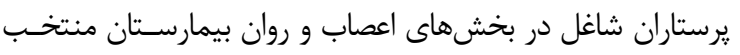
دانشكاه علوم بهزيستى و توانبخشى انجام دهند.

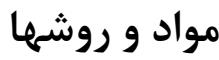

اين مطالعه توصيفى - مقطعى است در تمام بخشهــاى اعصـاب و

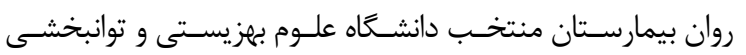

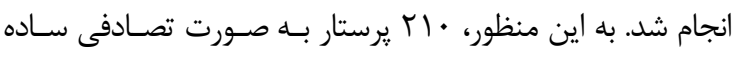

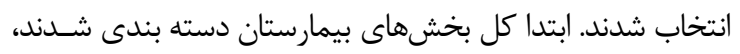

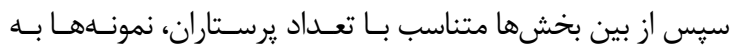

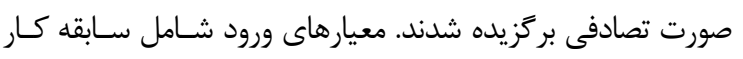

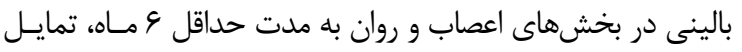

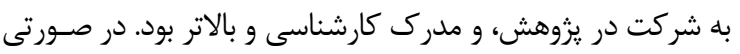

بيماران مىشود (ه). لذا سيستم خدمات بهداشتى مىتواند با ارتقا

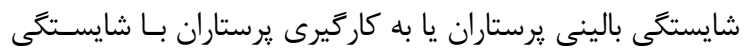
بيشتر، رضايت مددجويان را فراهم سازد (9).

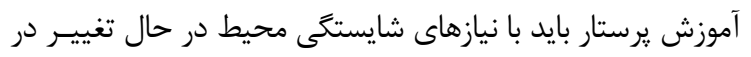

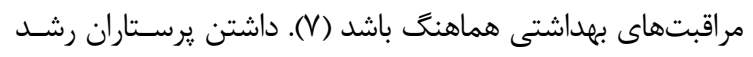

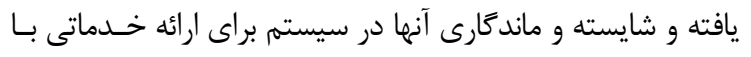

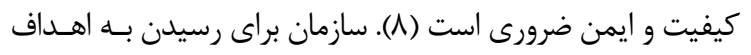

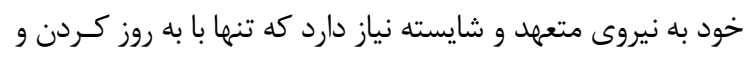

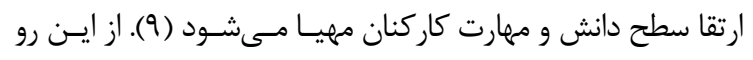

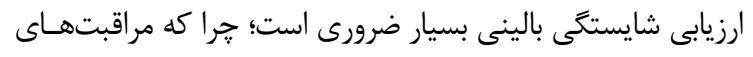

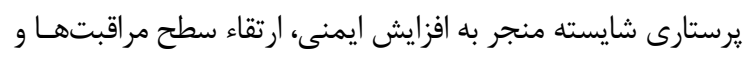

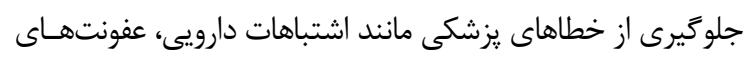

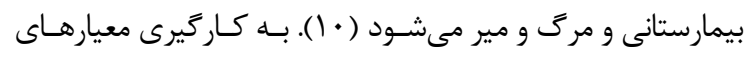

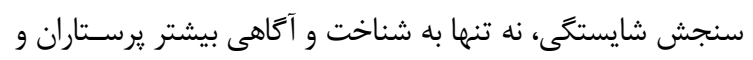

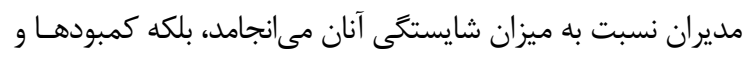

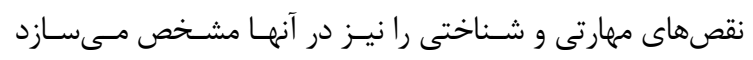
.(11.1r) مطالعات مختلفى در داخل و خارج از كشور به ارزيـابى شايسـتخى

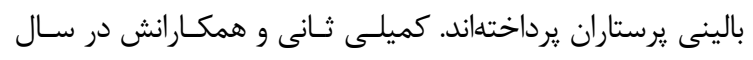

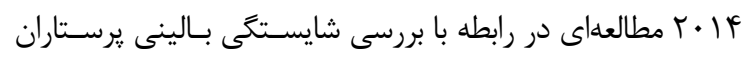

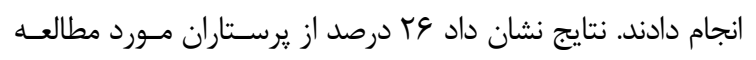

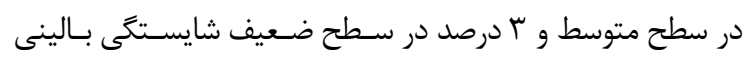

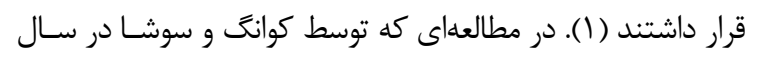

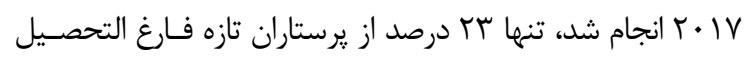

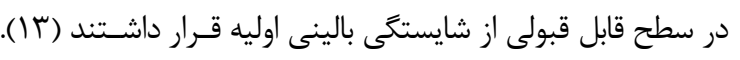

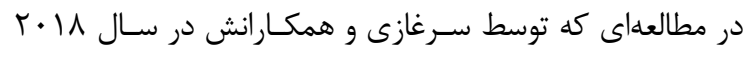

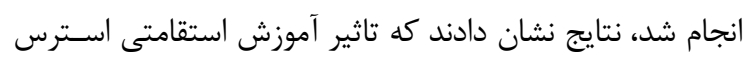
(stress inoculation training)

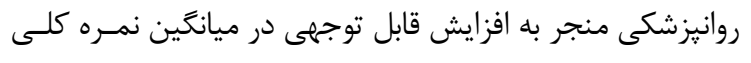

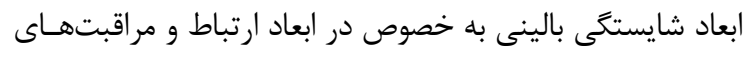

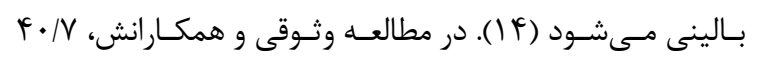

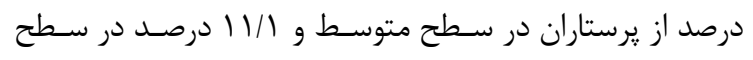

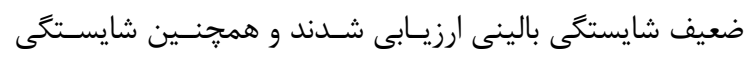

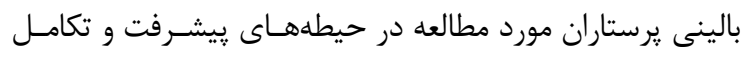

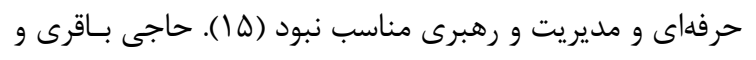

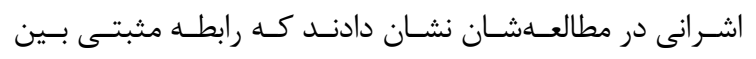
شايستخى بالينى برستاران و ميزان به كاركيرى اين شايستخى دانها

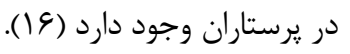

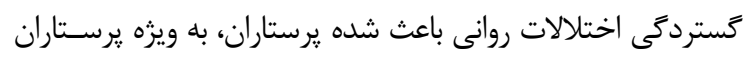

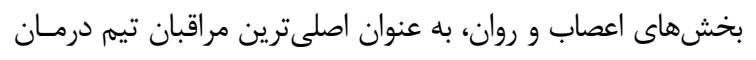


كميته اخلاق به شماره IR.IAU.TMU.REC.1397.003 دانشـعاه علوم يزشكى آزاد اسـلامى تهــران بــهـ تصـويب رسـيد. بــه منظــور

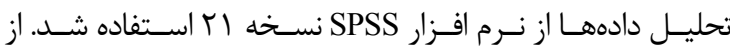
روشهاى آمارى توصيفى (جداول و شاخصهاى عددى، ميـانخين

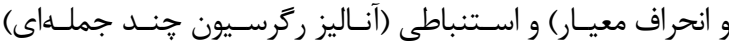

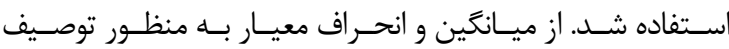
متغيرهـاى دموگر افيـك و شايسـتخى بــالينى، از درصـد فراوانسى، ميانگين و انحراف معيار براى توصيف حيطههاى شايستخى بـالينى

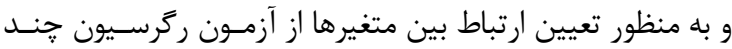
جملهاى و دوربـين واتسـن اسـتفاده شـد. در همــه مـوارد سـطح معنى دارى كمتر از ه • • • تعيين شد.

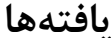

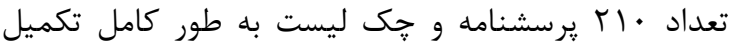
شد. مشخصات دمو گرافيك واحدهاى يزوهش در جدول 1 به اختصار بيان شده است.

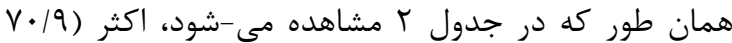

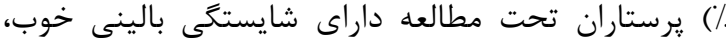

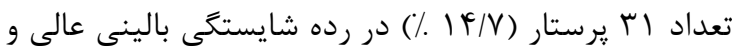

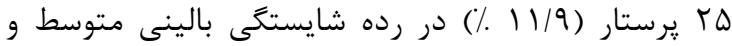

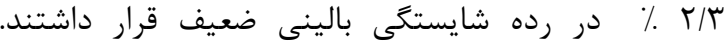

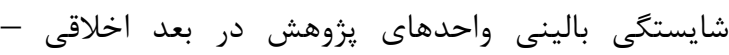

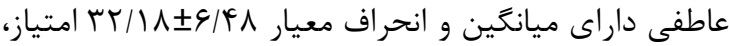
در بعد شايستخى در برقرارى ارتباط درمانى داراى ميانگين

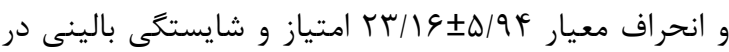
بعد مراقبتهاى ويزه در يرستاران مورد مطالعه داراى

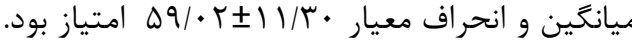

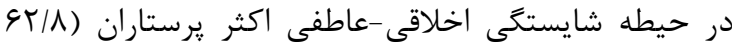
\%) در سطح خوب بودند. \&/l د درصد از يرستاران در سطح

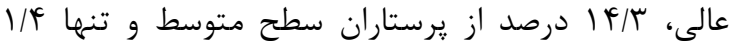
درصد از يرستاران در اين بعد در سطح ضعيف قرار داشتند.

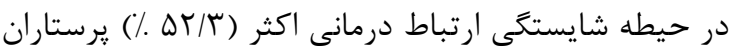
تحت مطالعه در سطح خوب بودند. | | ا درصد از يرستاران

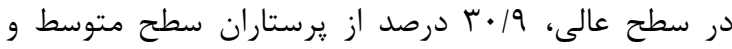
// درس درد از يرستاران در اين بعد در سطح ضعيف قرار داشتند. در حيطه شايستخى مراقبتهاى ويزه نيز اكثر (\% VI/F)

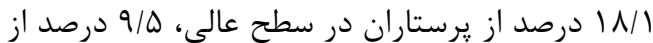

كه نمونهها يستهاى مديريتى و سريرستى در بيمارستان داشـتند

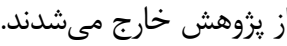
ابزار زرداورى اطلاعات، يرسشــنامه اطلاعـات دموگر افيـك (سـن، جنس، وضعيت تاهل، مقطع تحصيلى، داشتن فرزند، نوبت كـارى، سابقه كار، سابقه كار در بخش اعصاب و روان و اضافه كار) و جـك : جـ

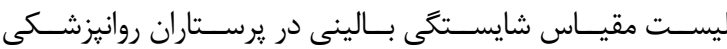
Clinical Competency of Mental Health ) CCMHN

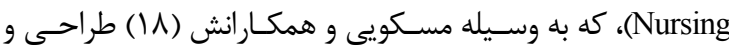

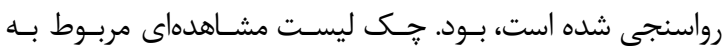
ارزيابى شايستخى بالينى يرسـتاران كـهـ شـامل هأ سـوال و داراى

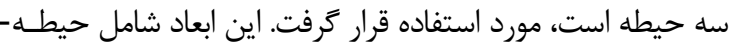

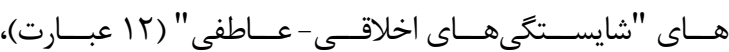

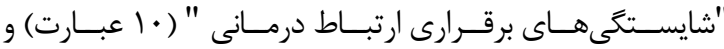
"شايستخى هاى مراقبت اختصاصى " (سب عبارت) بود. در اين ابـزار

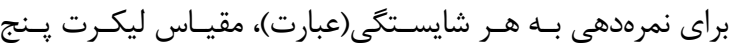

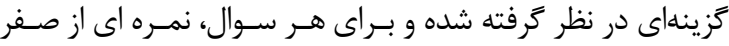
(َزينه هيج وقت) تا F (َزينه هميشه) در نظر گرفتـه شـد. جهـار

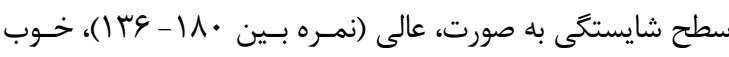

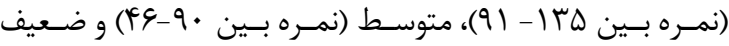
(نمره كمتر از \&\&) دسته بندى شـدند. روايـى و يايـايى ايـن ابـزار توسط مسكويى و همكاران تاييـد شـده اسـت. در مطالعـه حاضـر يايايى ابزار از طريق باز آزمايى بررسى شد؛ به اين ترتيب كــه ابتـدا

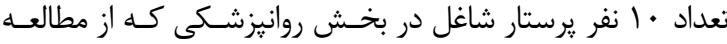

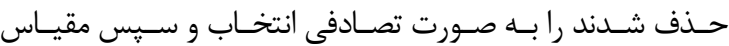
شايستخى بالينى در برستاران روانيزشكى CCMHN، براى دو بـار

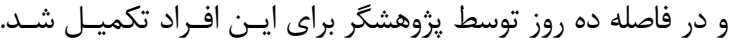

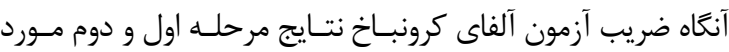
محاسبه قرار رَفت. قابليت اطمينان ابزار توسط آلفـاى كرونبـاخ از

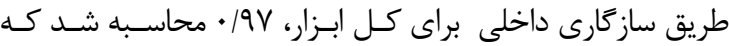
نشان دهنده يايايى مناسب ابزار است.

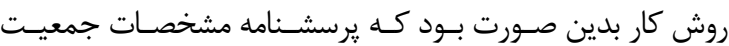
شناختى توسط واحدهاى يزوهش تكميل شـد. سـيس يزوهشــر

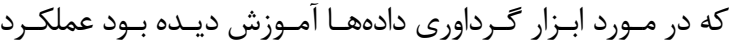

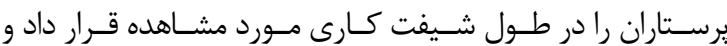
عملكرد آنها را در جك ليست مقياس شايستتى بالينى ثبت كرد. ز جمله ملاحظات اخلاقى اين يـرّوهش، ارائهـ توضـيحات لازم در

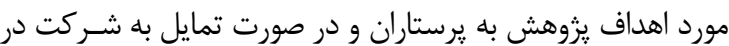
مطالعه اخذ رضايت نامه كتبى آكاهانه، عدم نياز به درج نـام و نـام خانوادَى و محرمانه بودن اطلاعات فردى بود. اين مطالعـه توسـط شوراى يروهش و تحصيلات تكميلى دانشكده پيرستارى- مامايى و 


\begin{tabular}{|c|c|c|c|c|c|}
\hline \multirow[b]{2}{*}{ انحراف معيار } & & & \multicolumn{3}{|c|}{ جدول ا. متغيرهاى جمعيت شناختى يرستاران } \\
\hline & ميانگين & 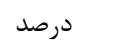 & فراوانى & 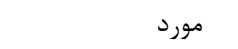 & متغير \\
\hline & - & 4. & ITS & 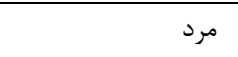 & جنسيت \\
\hline & - & r. & $\Delta F$ & زن & \\
\hline & - & $r y / \Lambda$ & vr & 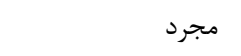 & تاهل \\
\hline & - & $9 \Delta / r$ & irv & 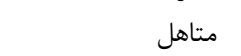 & \\
\hline & - & $e v / l$ & १९ & 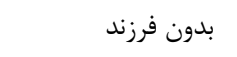 & 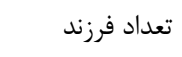 \\
\hline & - & $r \cdot / \Delta$ & st & يك & \\
\hline & - & $1 \cdot / 4$ & tr & دو & \\
\hline & - & $11 / 9$ & $r \Delta$ & سه و بيشتر & \\
\hline & - & 9v/1 & r.r & 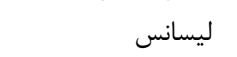 & تحصيلات \\
\hline & - & $r / 9$ & s & فوق ليسانس و بالاتر & \\
\hline & - & IV/9 & rr & صبح & نوبت كارى \\
\hline & - & $r / F$ & $\Delta$ & عصر & \\
\hline & - & $1 \pi / r$ & rA & شب & \\
\hline & - & 91 & $M \Lambda$ & در :رخش & \\
\hline & - & $\Delta / V$ & ir & دو شيفت & \\
\hline G/VD \pm & rr/rr & - & - & سال س & سن \\
\hline$V / \cdot 1 \pm$ & $1 \cdot / 4$ & - & - & سال & كل سابقه كارى \\
\hline$\varphi / l \pm$ & $V / I V$ & - & - & صاب و روان & سابقه كارى بخش \\
\hline$\vdash q / r q \pm$ & $1.1 / 4 \Delta$ & - & - & (ob & اضافه كار(ساعت د \\
\hline
\end{tabular}

اضافه كار، ميانكَين شايستگى اخلاقى/عاطفى ع/؟ كاهش

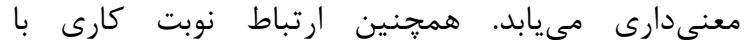

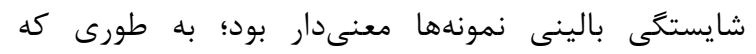

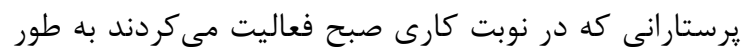

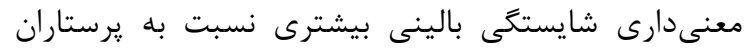

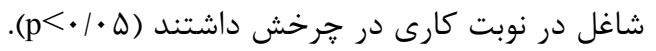

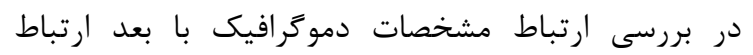

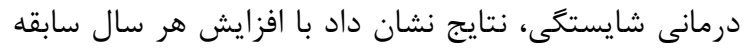

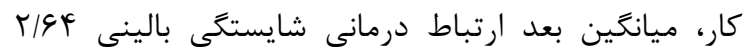

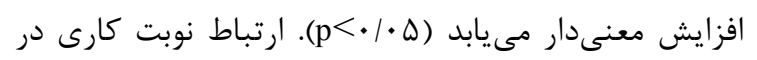

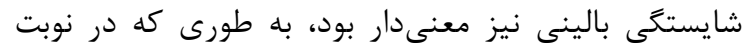

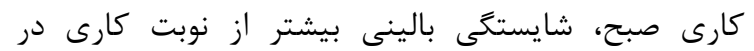

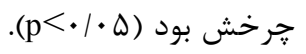
در بررسى ارتباط مشخصات دموكرافيك با بعد مراقبتهاى

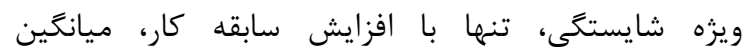

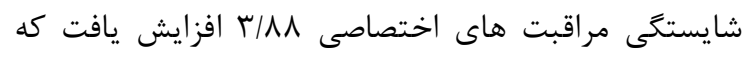

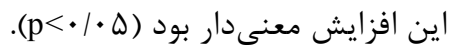
همجنين مشخص شد شايستخى بالينى در سه حيطه

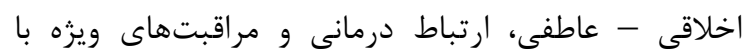
متغيرهاى جنسيت، وضعيت تاهل، تعداد فرزندان،
يرستاران در سطح متوسط و تنها 9/• درصد از يرستاران در اين بعد در سطح ضعيف قرار داشتند (جدول كار).

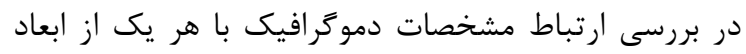

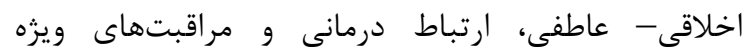

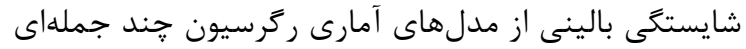

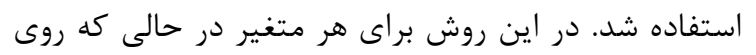

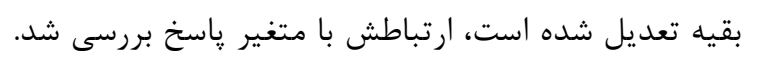

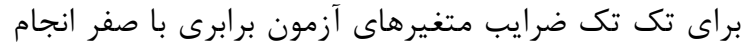

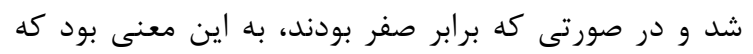

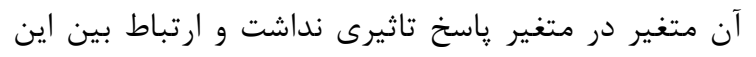

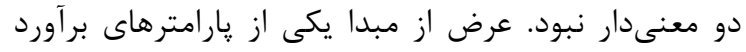

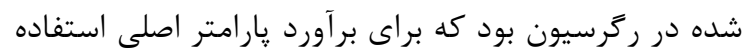

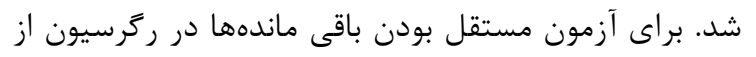

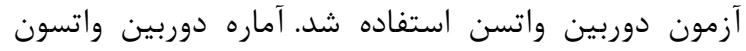

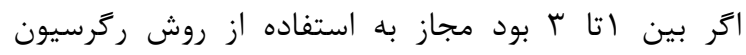

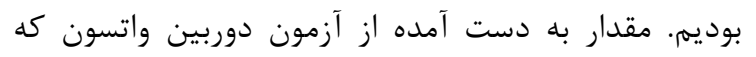

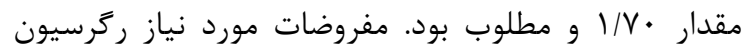
خطى بررسى شد و برقرار بود.

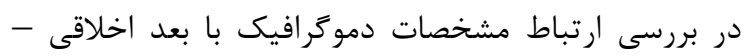

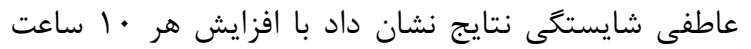


جدول r. توزيع فراوانى و ميانگين و انحراف معيار حيطههاى شايستگى بالينى در يرستاران

\begin{tabular}{|c|c|c|c|c|c|}
\hline انحر اف معيار & ميانگين & د مرصد & 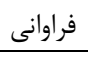 & \multicolumn{2}{|c|}{ حيطههاى شايستگى بالينى } \\
\hline & & $r / \Gamma$ & $\Delta$ & ضعيف & شايستكى بالينى كل \\
\hline & & $11 / 9$ & ra & متوسط • 9-94 & \\
\hline & & $v \cdot 19$ & 149 & خوبهr|-19 & \\
\hline \multirow{5}{*}{$\varepsilon / \uparrow \wedge \pm$} & & $I F / V$ & 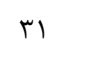 & عالى ·1 |- عس|| & \\
\hline & TT/MA & $1 / 4$ & $r$ & ضعيف |r> & اخلاقى عاطفى \\
\hline & & $\mid f / r$ & $r \cdot$ & متوسط IF-YY & \\
\hline & & GY/A & Irt & 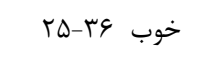 & \\
\hline & & $r \mid / 4$ & id & 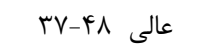 & \\
\hline \multirow[t]{4}{*}{$\Delta / q \uparrow \pm$} & $r m / l e$ & $r / \Lambda$ & $\wedge$ & ضعيف > | 1 & ارتباط درمانى \\
\hline & & $r \cdot / 9$ & $9 \Delta$ & متوسط ·r-II & \\
\hline & & $\Delta r / T$ & 11. & خوب •r-rا & \\
\hline & & $\mid r / \Lambda$ & rV & عالى .r-r & \\
\hline \multirow[t]{4}{*}{$11 / \pi \cdot \pm$} & $\Delta q / \cdot r$ & $\cdot 19$ & $r$ & ضعيف > Yr & مراقبت هاى ويزه \\
\hline & & $9 / 0$ & $r \cdot$ & متوسط rF-F\& & \\
\hline & & $V I / 4$ & 10 & خوب FV-\&q & \\
\hline & & $11 / 1$ & rᄉ & ع.-9r عالى & \\
\hline
\end{tabular}

جدول rا. رابطه متغيرهاى دموَّرافيك يرستاران با ميزان شايستَى بالينى آنها

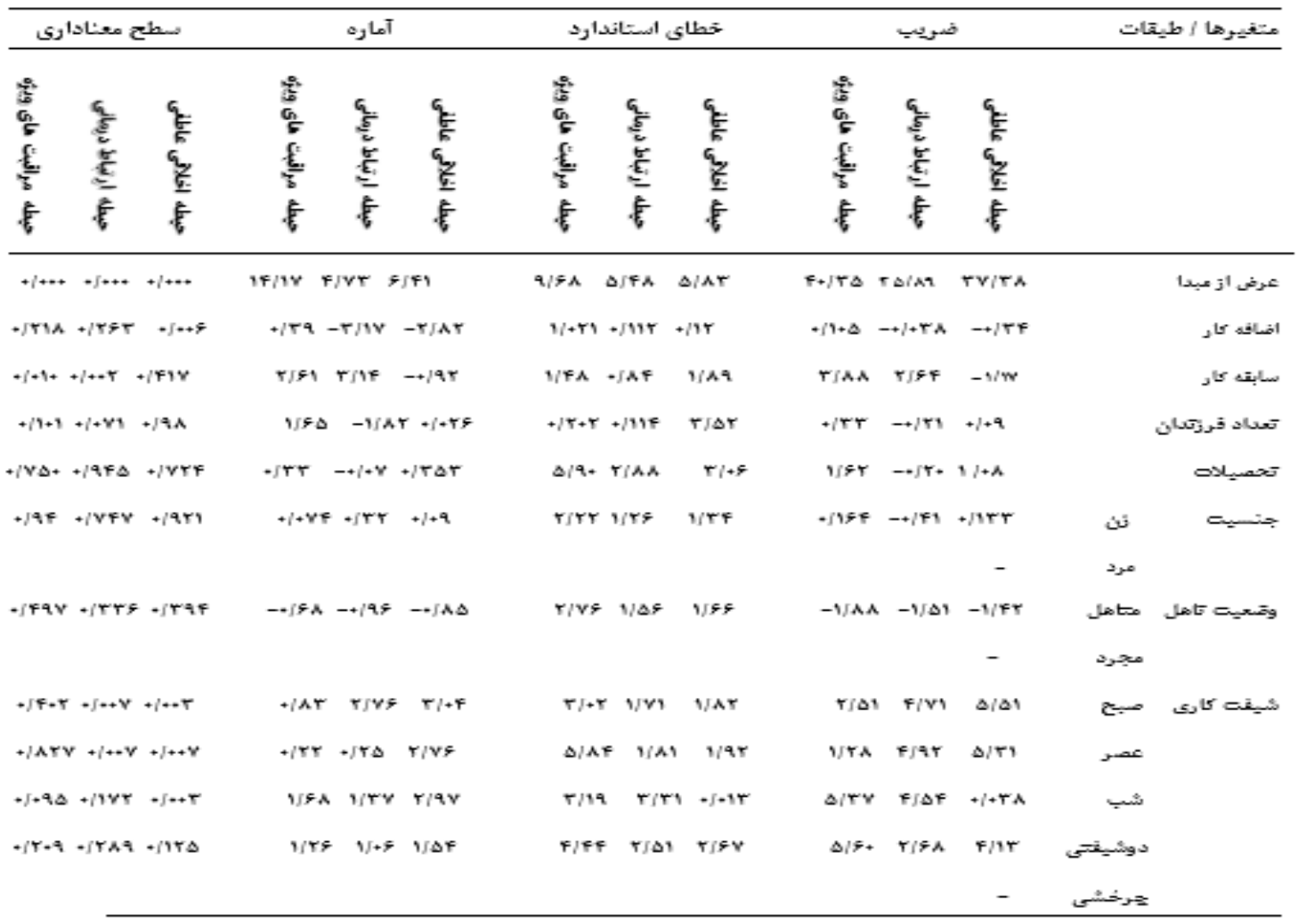

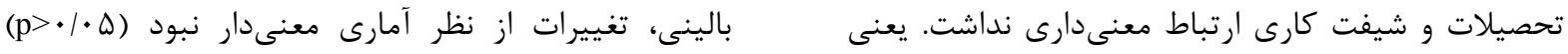

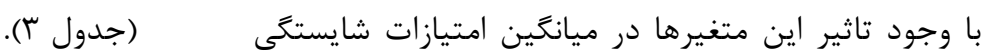


ضرورى است كه يرستاران مهارت خود را در اين زمينه افزايش دهند. وظيفه يك يرستار برآورده ساختن نيازهاى

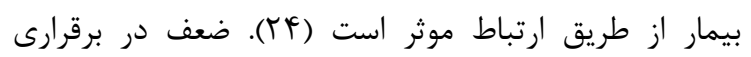

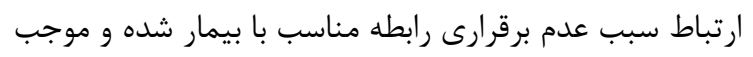

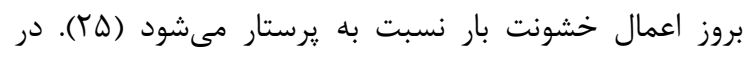

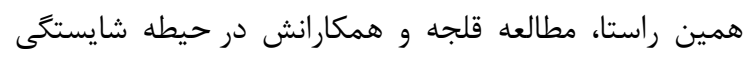

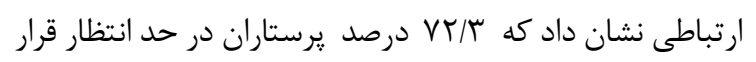

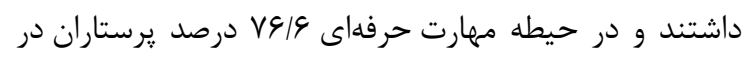

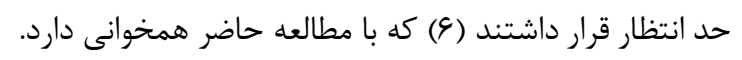
در مطالعه حاضر بين متغيرهاى سابقه كار، اضافه كار و نوبت داضن

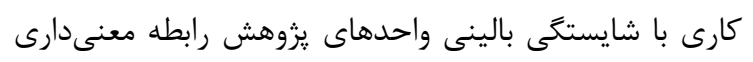

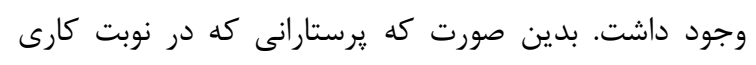

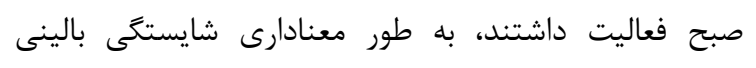

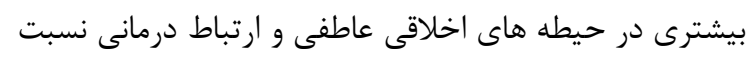

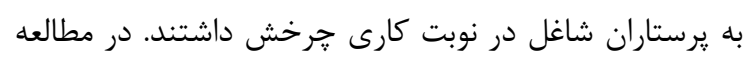

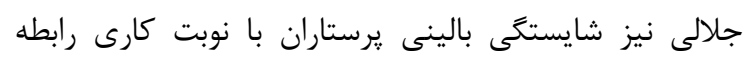

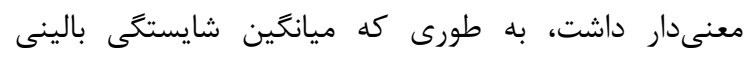

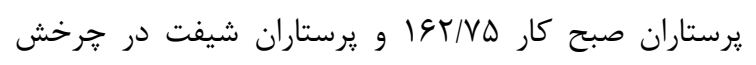

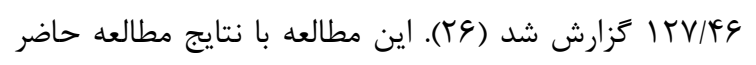

همخوانى دارد. نتايج بدست آمده از مطالعه ما بيانكر اين است با افزايش

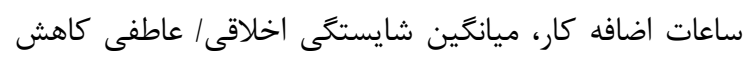

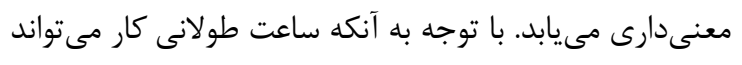

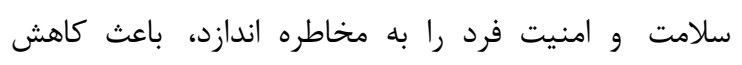
هوشيارى، شايستخى و كاهش بهره ورى در شغل نيز مى إشود (TV)

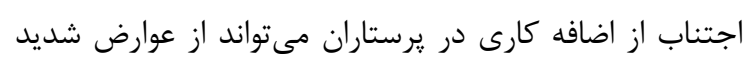

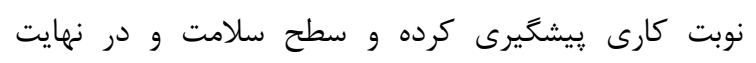

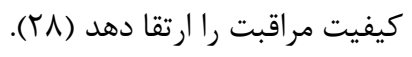

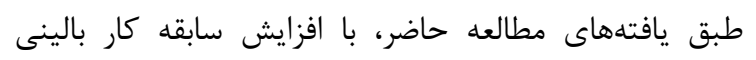

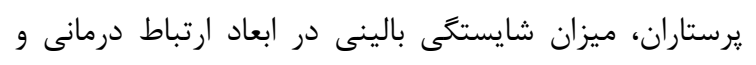

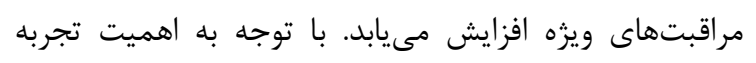

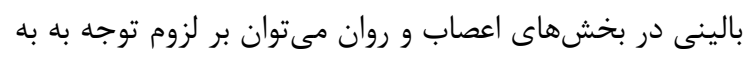

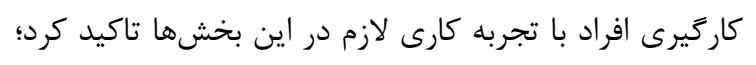

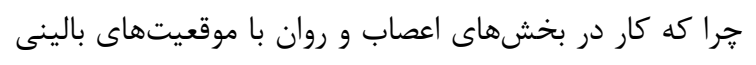

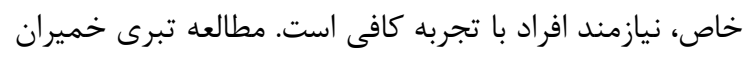

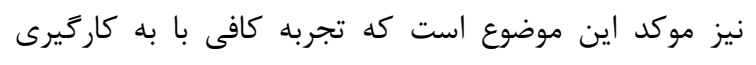

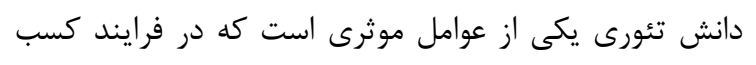

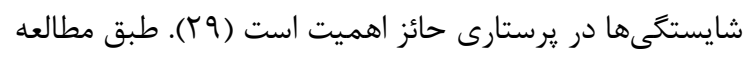
كيم، شايستخى بالينى يرستاران متاهل و داراى سابقه بيشتر،
در اين يزوهش شايستخى بالينى برستاران شاغل در بخشهاى

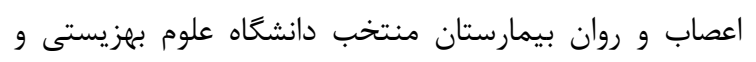

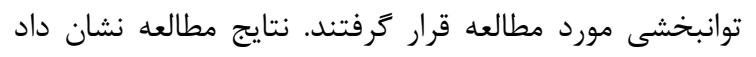

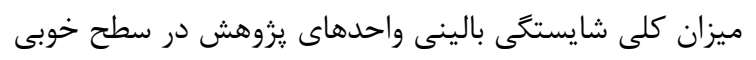

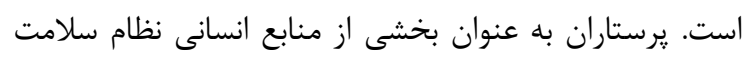

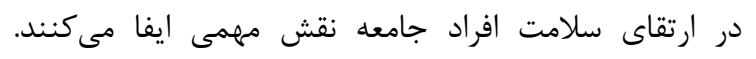

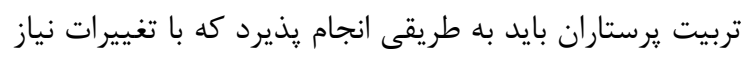

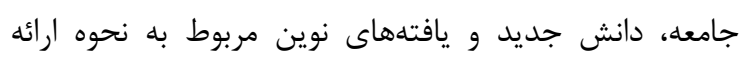

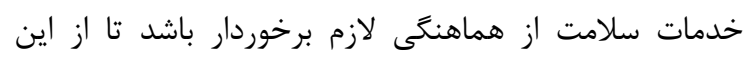

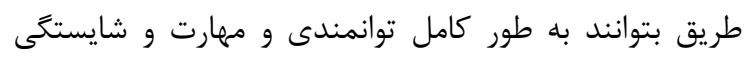

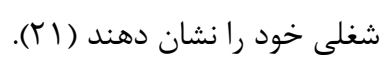

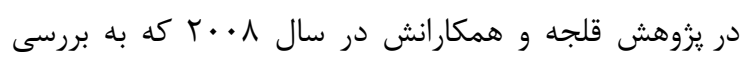

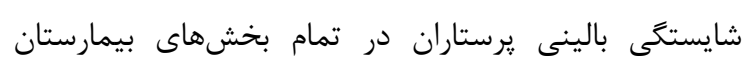

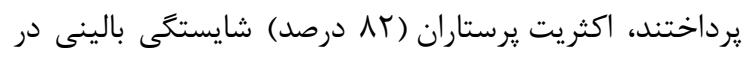

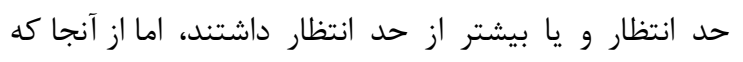

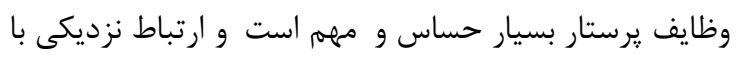

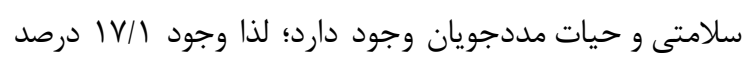

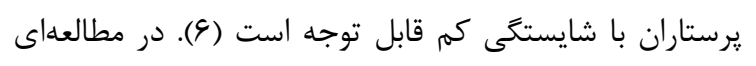

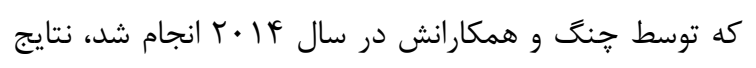

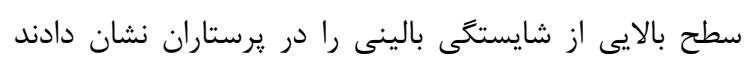

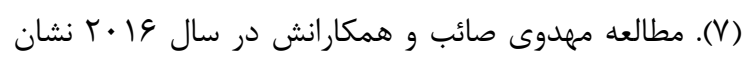

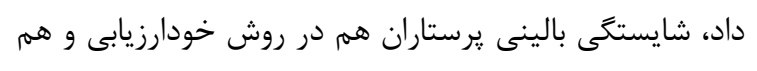

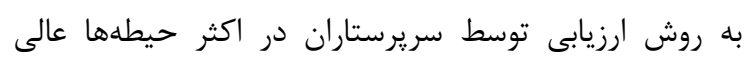

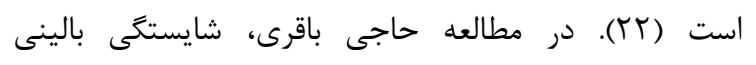

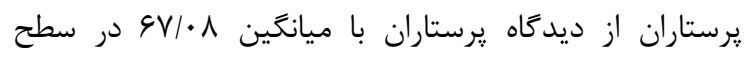

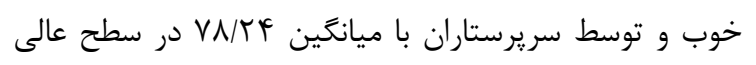

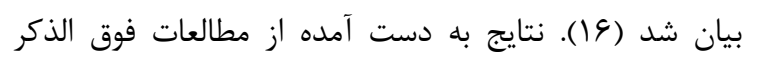

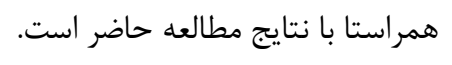
در ارتباط با حيطه شايستخى اخلاقى - عاطفى نتايج نشان انسان

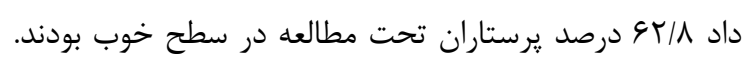

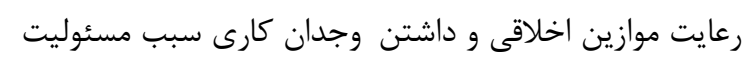

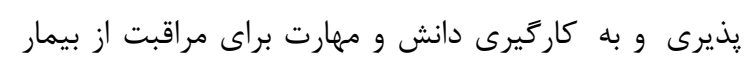

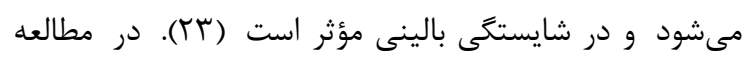

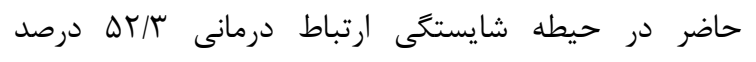

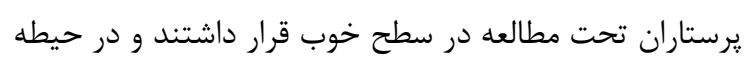

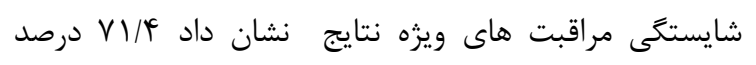

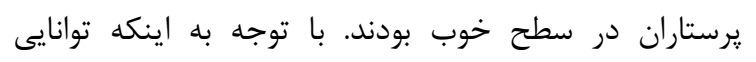

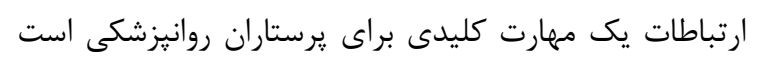




$$
\begin{aligned}
& \text { مديران يرستارى از سطح شايستخى بالينى يرستاران شاغل در } \\
& \text { بخشهاى اعصاب و روان در جهت سطح بندى يرستاران بر }
\end{aligned}
$$

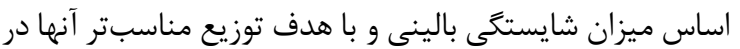

$$
\begin{aligned}
& \text { بخش هاى مختلف استفاده نمايند. } \\
& \text { از محدوديتهاى مطالعه حاضر، استفاده از روش مشاهده }
\end{aligned}
$$

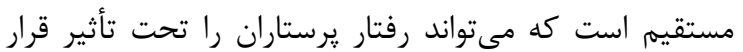

$$
\begin{aligned}
& \text { دهد كه از كنترل يزوهشگر خارج بود. محدوديت ديگر مربوط } \\
& \text { به كمبود مطالعات مشابه در خصوص شايستگى بالينى }
\end{aligned}
$$

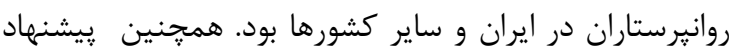

$$
\begin{aligned}
& \text { مىشود در يروهش هاى آتى، شايستگى بالينى روان يرستاران } \\
& \text { توسط مشاهده، خودارزيابى و ارزيابى توسط مديران يرستارى } \\
& \text { با يكديخر مقايسه شود. }
\end{aligned}
$$

\section{تقدير و تشكر}

بدين وسيله از تمامى يرستاران شركت كننده در اين مطالعه كه با محققان همكارى كردند سياسگزارى مىشود. اين مطالعه حاصل يايان نامه دانشجويى در مقطع كارشناسى ارشد رشته روان :رستارى است. بدين وسيله از حمايتهاى مسئولين دانشكده يرستارى و مامايى دانشگاه علوم يزشكى آزاد اسلامى

$$
\text { تهران در انجام مطالعه تقدير مىشود. }
$$

بالاتر از ساير يرستاران بود (•r). در مطالعه كه توسط فلينكمن و همكارانش صورت گرفت نشان داد شايستگى بالينى :يرستاران با افزايش تجربه كارى، سن و تحصيلات ارتباط مستقيمى دارد (1). اين مطالعات با نتايج مطالعه حاضر همراستا است. اين در حالى است كه طبق مطالعات وثوقى و همكارانش و اديب حاجى باقرى و اشراقى، بين شايستخى بالينى : يرستاران با متغيرهاى وضعيت تاهل،

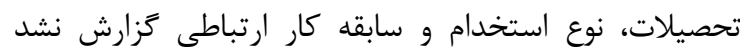

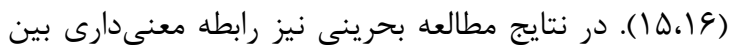
سن، سابقه كار كلى و سابقه كار در بخش فعلى يرستاران با بإن ميانگين شايستخى بالينى آنها وجود نداشت. طبق يابق يافتههاى

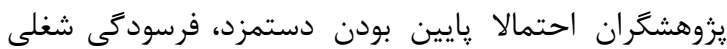
ناشى از كار سنگين و زياد و نارضايتى شغلى موجود در بين يرستاران مىتواند باعث شود كه برخى از يرستاران همراه با بان

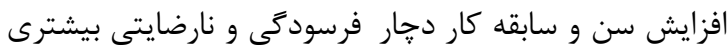
شده و اين نارضايتى را در ارزيابىهاى خود به نمايش بحذارند

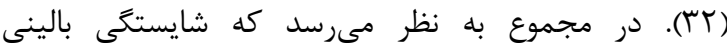

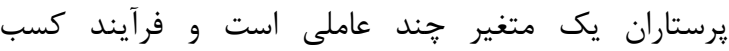
شايستخى بالينى بر اساس رابطه بين سه عامل مهرم اخلاق، تجربه كارى مفيد و عوامل محيطى حاصل مىشود (Yr). نتايج اين ارزيابىها مىتواند در سنجش نيازهاى آموزشى ميى

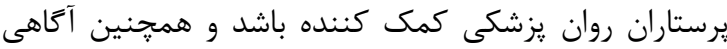

\section{REFERENCES}

1. Komeili Sani H, Etemadi A, Bostani H, Bahraini M, Hakim A. The relationship between clinical competency and nurses' job stress in hospitals affiliated to Ahwaz University of Medical Sciences in 2013. Journal of Nursing and Midwifery. 2014; 40: 41-6. [In Persian]

2 - Nilsson J, Johansson E, Egmar AC, Florin J, Leksell J, Lepp M, et al. Development and validation of a new tool measuring nurses self-reported professional competence_-The nurse professional competence (NPC) Scale. Nurse 2014;34:574-80.

3- Mohtashami J, Pazargadi M, Salsali M, Manoochehri H, Alavi Majd H. Developing Mental Health Nursing Students' Clinical Competency Model. International Journal of Physical and Social Sciences. 2014; 4: 261-263. [In Persian]

4- Bagheri Nesami M, Rafiei F, Parvizi S, Esmaeili R. Nursing competency concept analysis: Qualitative research and presentation of a hybrid model. Journal of Mazandaran University of Medical Sciences 2008;18::35-49. [In Persian]

5- Lyngfoss B, Bjørk IT. Self-evaluation of competence by nurses working offshore. Norwegian J Clin Nurs 2017; 11:12-22.

6- GHelje M, GHeljaee F, Mazlom A. Correlation between nurse's clinical competence and patient satisfaction with nursing. Journal of Shahid Beheshti School of Nursing and Midwifery 2008;18:12-9. [In Persian]

7- Cheng CY, Tsai HM, Chang CH, Liou SR. New graduate nurses' clinical competence, clinical stress, and intention to leave: a longitudinal study in Taiwan. Sci World J 2014;20:14-19.

8- Coventry TH, Maslin-Prothero S, Smith G. Organizational impact of nurse supply and workload on nurses continuing professional development opportunities: an integrative review. J Adv Nurs 2015;71:2715-27.

9- Casey M, Cooney A, O'Connell R, Hegarty JM, Brady AM, O'Reilly P, et al. Nurses', midwives' and key stakeholders' experiences and perceptions on requirements to demonstrate the maintenance of professional competence. J Adv Nurs 2017;73:653-64

10- Lakanmaa RL, Suominen T, Perttilä J, Ritmala-Castrén M, Vahlberg T, Leino-Kilpi H. Basic competence in intensive and critical care nursing: development and psychometric testing of a competence scale. J Clin Nurs 2014;23:799-810. 
11- Numminen O, Laine T, Isoaho H, Hupli M, Leino-Kilpi H, Meretoja R. Do educational outcomes correspond with the requirements of nursing practice: educators' and managers' assessments of novice nurses' professional competence? Scand J Caring Sci 2014;28:812-21.

12- Bahreini M, Moattari M, Kaveh MH, Ahmadi F. A comparison of nurses' clinical competences in two hospitals affiliated to Shiraz and Boushehr Universities of Medical Sciences: A Self-Assessment. Iran J Med Sci 2010;10:101-10. [In Persian]

13- Kavanagh JM, Szweda C. A crisis in competency: The strategic and ethical imperative to assessing new graduate nurses' clinical reasoning. Nursing Education Perspectives 2017;38:57-62.

14- Sargazi O, Foroughameri G, Miri S, Farokhzadian J. Improving the professional competency of psychiatric nurses: Results of a stress inoculation training program. Psychiatr Res 2018;270:682-7.

15- Namadi-Vosoughi M, Tazakkori Z, Habibi A, Abotalebi-Daryasari G, Kazemzadeh R. Assessing Nursing Graduates' Clinical Competency from the Viewpoints of Graduates and Head Nurses. Journal of Health and care 2014;16:66-73. [In Persian]

16- Adib Hajbaghery M, Eshraghi Arani N. Assessing nurses' clinical competence from their own viewpoint and the viewpoint of head nurses: a descriptive study. Iran Journal of Nursing. 2018;31:52-64. [In Persian]

17- AliZadeh S, Mokhtari Nouri J, Taqwa A, Azizi M. Effect of implementation of evidence-based nursing care guidelines on the standard of quality of care in the psychiatric ward. Journal of Military Sciences 2016; 3: 123-132. [In Persian]

18- Sadeghi S, Dasht Bozorgi B, Latifi M. Comparison of mental health and marital satisfaction of nurses working in psychiatric and other departments of teaching hospitals of Jondishapoor, Ahwaz, Jundishapur University of Medical Sciences, Ahvaz, Iran. Nursing and Midwifery Clinical Journal 2016;6: 53-65. [In Persian]

19- Vaghee S, Meshkin Yazd A, Asgharipour N, Ebrahimzadeh S. The effect of critical thinking training on nurses' job stress in psychiatric ward. Journal of Fundamentals of Mental Health 2014; 16: 12-21. [In Persian]

20- Dean AJ, Gibbon P, McDermott BT, Davidson T. Exposure to aggression and the impact on staff in a child and adolescent inpatient unit. Arch Psychiatr Nurs 2010; 24: 15-26.

21- Memarian R, Salsali M, Vaaki Z, Ahmadi F, Hajizade A. Effective factors in the process of achieving clinical competency. Scientific Journal of Zanjan University of Medical Sciences 2007;14:40-9. [In Persian]

22- Mahdavi Saeb F, Hanifi N, Kamali K. A comparative study of clinical competency of nurses in intensive care units by self-assessment and evaluation by head nurses of Zanjan University of Medical Sciences. Nursing and Midwifery Preventive Care Magazine 2016;6: 72-82. [In Persian]

23- Parsa Yekta, Z, Ramezani Badr F, Khatoni A. Nursing students' views about clinical competency and achievement rate. Iranian Journal of Nursing Research 2006; 1: 7-14. [In Persian]

24- Moskoei S, Mohtashami J, Ghalenoeei M, Nasiri M, Tafreshi MZ. Development and psychometric properties rating scale of "clinical competency evaluation in mental health nurses": Exploratory factor analysis. Electr Phys 2017;9:4155.

25- Jahani M. Survey the level of violence incidence against nurses from their viewpoint and related factors in educational medical centers in Rasht in 2012 [MSc Thesis]. Rasht: Guilan University of Medical Sciences; 2012. [In Persian]

26- Jalali A, Kazemi S, Khatooni A, Rezaei M. Evaluation of clinical competency of nurses in career specially in hospitals affiliated to Kermanshah Medical Sciences University. Quarterly Journal of Clinical Care Research. 2015; 3: 10-16. ([In Persian]

27- Machi MS, Staum M, Callaway CW, Moore C, Jeong K, Suyama J, et al. The relationship between shift work, sleep, and cognition in career emergency physicians. Acad Emerg Med 2012; 19: 85-91.

28- Farzianpour F, Ansari Nosrati S, Rahimi Froshani A. Survey of relationship between nurses shift and personality characteristics in private hospitals in Tehran City. Journal of Paramedical Sciences, Tehran University of Medical Sciences 2016; 10: 419-428. [In Persian]

29- Khomeiran RT, Yekta Z, Kiger A, Ahmadi F. Professional competence: factors described by nurses as influencing their development. International Nursing Review 2006;53:66-72. [In Persian]

30- Kim MJ, Kim YJ. Variables affecting nursing competency of clinical nurses. Indian J Sci Technol 2015;8:1-9.

31- Flinkman M, Leino-Kilpi H, Numminen O, Jeon Y, Kuokkanen L, Meretoja R. Nurse Competence Scale: a systematic and psychometric review. J Adv Nurs 2017;73:1035-50.

32- Bahreini M, Moattari M, Kaveh MH, Ahmadi F. Self-assessment of the clinical competence of nurses in a major educational hospital of Shiraz University of Medical Sciences. Journal of Jahrom University Medical Sciences 2010; 8: 28-36. [In Persian] 